\title{
Doctor, I say yes to a good old coronary bypass operation and no to your new blood pump!
}

\author{
Michel Carrier, MD, MBA, ${ }^{a}$ and Louis Perrault, $\mathrm{MD}^{\mathrm{b}}$
}

\footnotetext{
From the ${ }^{\mathrm{a} D e p a r t m e n t}$ of Surgery, and the ${ }^{\mathrm{b}}$ Division of Cardiac Surgery, Montreal Heart Institute, Université de Montréal, Montreal, Quebec, Canada.

Disclosures: Authors have nothing to disclose with regard to commercial support.

Received for publication March 14, 2017; accepted for publication March 17, 2017; available ahead of print April $21,2017$.

Address for reprints: Michel Carrier, MD, MBA, Department of Surgery, Montreal Heart Institute, 5000 Belanger St, Montreal, Quebec H1T 1C8, Canada (E-mail: michel.carrier@icm-mhi.org).

J Thorac Cardiovasc Surg 2017;154:526-7

$0022-5223 / \$ 36.00$

Copyright (c) 2017 by The American Association for Thoracic Surgery http://dx.doi.org/10.1016/j.jtcvs.2017.03.056
}

Patients with end-stage heart failure represent a growing concern, and the demand for new treatments remains high among the public. Even though new blood pumps and devices are now available, heart transplantation remains the most standardized approach with the best predictable results. Donor organ shortage reduces the availability of heart transplants, however, and transplantation will never become a definitive answer to this public health problem.

In this issue of the Journal, Kawajiri and colleagues ${ }^{1}$ have reported on 133 patients evaluated for advanced therapy with left ventricular ejection fraction less than $20 \%$ and maximal oxygen uptake less than $14 \mathrm{~mL} / \mathrm{min} / \mathrm{m}^{2}, 122$ $(92 \%)$ of whom underwent conventional surgery, that is coronary artery bypass grafting surgery (CABG). Inhospital mortality averaged $12 \%$, and 5-year survival was $72 \%$. At 5 and 10 years after surgery, the survivals of transplant-eligible patients who underwent conventional

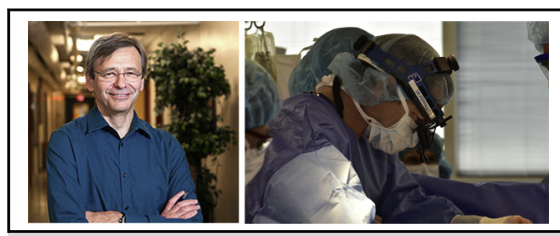

Michel Carrier, MD, MBA, and Louis Perrault, MD

Central Message

Coronary artery bypass grafting surgery remains a good treatment option to consider for selected patients with end-stage heart failure.

See Article page 517. surgery $(68 / 133,51 \%)$ were identical to those of a cohort of heart transplant recipients, and the survivals of transplant-ineligible patients $(65 / 133,49 \%)$ were similar to those of a cohort of patients who received destination left ventricular assist device therapy.

Kawajiri and colleagues ${ }^{1}$ assessed myocardial viability with magnetic resonance imaging or positron emission tomographic scanning to establish the potential for left ventricular recovery after CABG. In-hospital mortality for patients undergoing isolated $\mathrm{CABG}$ was $2.3 \%$, and this increased to $14.3 \%$ for those undergoing $\mathrm{CABG}$ with

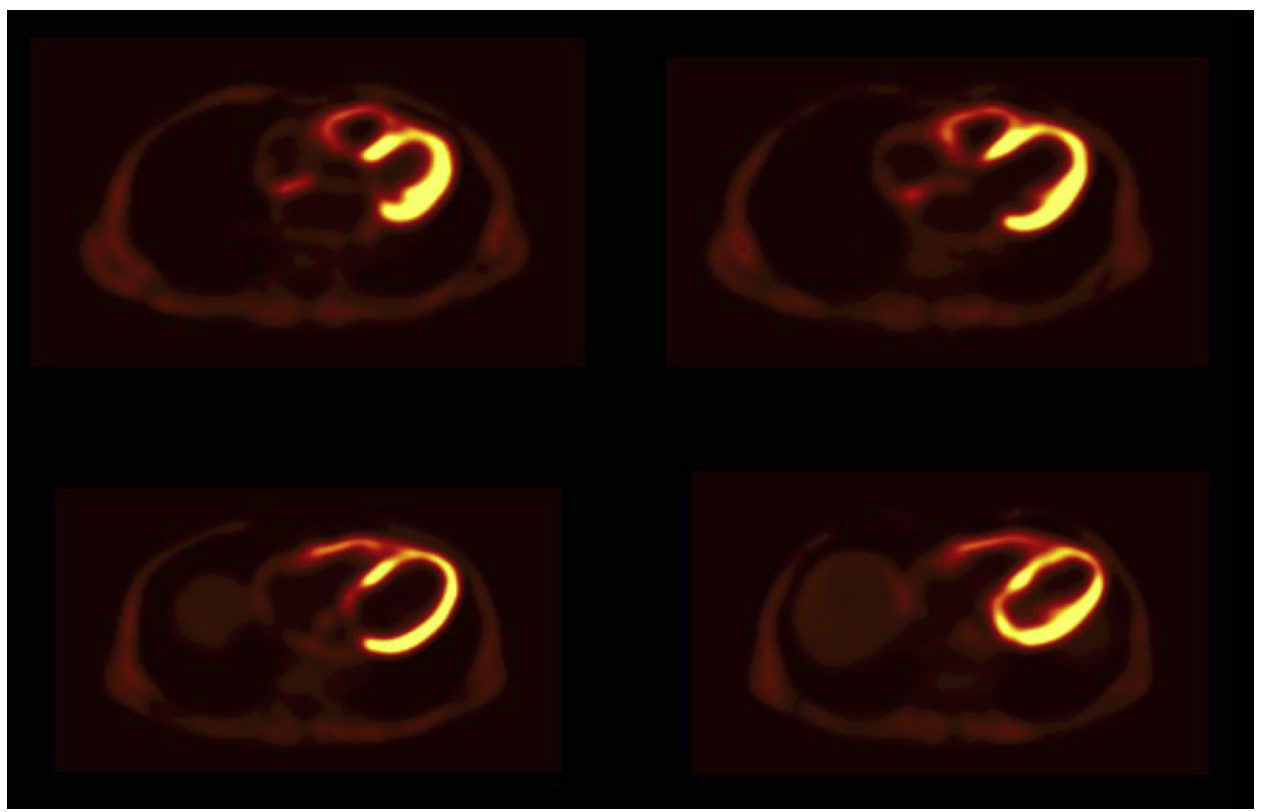

FIGURE 1. Positron emission tomographic scan images showing good myocardial viability despite low ejection fraction $(<20 \%)$. 
associated procedures (mitral valve [MV] repair or replacement and left ventricular reconstruction). From the Surgical Treatment for Ischemic Heart Failure Extended Study (STICHES) trial, Velazquez and associates ${ }^{2}$ concluded that after 9.8 years of follow-up CABG was associated with more favorable results than medical therapy alone in patients with heart failure, left ventricular dysfunction, and coronary artery disease. The study of Kawajiri and colleagues ${ }^{1}$ shows that high-risk CABG, although associated with a higher in-hospital mortality when combined with MV repair or replacement, results in 5- and 10-year survivals similar to those associated with heart transplantation and destination left ventricular assist device treatment.

In our mind, standard and isolated CABG surgery should be offered to patients with end-stage heart failure who show good target coronary arteries to bypass, ideally with two internal thoracic arteries, when significant myocardial viability is determined on positron emission tomographic scan (Figure 1). CABG associated with MV repair or replacement carries a higher in-hospital mortality, averaging $11 \%$ in the series of Kawajiri and colleagues. ${ }^{1}$ Maltais and coworkers ${ }^{3}$ reported 30-day mortality averaging
$7 \%$ in a series of patients undergoing CABG with $\mathrm{MV}$ repair or replacement for end-stage ischemic cardiomyopathy. Poor coronary targets and the absence of myocardial viability on noninvasive testing should incline these patients toward long-term left ventricular assist device therapy. Isolated or complex CABG surgery, including MV repair or replacement, should only be offered to patients with endstage heart failure if it can be performed with low inhospital mortality, probably lower than $7 \%{ }^{4}$

\section{References}

1. Kawajiri H, Manlhiot C, Ross H, Delgado D, Billia F, McDonald M, et al High-risk cardiac surgery as an alternative to transplant or mechanical support in patients with end-stage heart failure. J Thorac Cardiovasc Surg. 2017;154: 517-25.

2. Velazquez EJ, Lee KL, Jones RH, Al-Khalidi HR, Hill JA, Panza JA, et al; STICHES Investigators. Coronary-artery bypass surgery in patients with ischemic cardiomyopathy. N Engl J Med. 2016;374:1511-20.

3. Maltais S, Tchantchaleishvili V, Schaff HV, Daly RC, Suri RM, Dearani JA, et al Management of severe ischemic cardiomyopathy: left ventricular assist device as destination therapy versus conventional bypass and mitral valve surgery. J Thorac Cardiovasc Surg. 2014;147:1246-50.

4. John R, Holley CT, Eckman P, Roy SS, Cogswell R, Harvey L, et al. A decade of experience with continuous-flow left ventricular assist devices. Semin Thorac Cardiovasc Surg. 2016;28:363-75. 